$\begin{array}{lc}\text { Salford University } & 4 \\ \text { Strathclyde University } & 4 \\ & \\ \text { Northumbria University } & 3 \mathrm{a} \\ \text { Queen's University Belfast } & 3 \mathrm{a} \\ \text { Robert Gordon University } & 3 \mathrm{a} \\ & \\ \text { Brighton University } & 3 \mathrm{~b} \\ \text { De Montfort University } & 3 \mathrm{~b} \\ \text { Manchester Metropolitan University } & 3 \mathrm{~b} \\ \text { Queen Margaret College } & 3 \mathrm{~b} \\ \text { University of Central England } & 3 \mathrm{~b} \\ \text { University of Wales, Aberystwyth } & 3 \mathrm{~b} \\ \text { University of the West of England } & 3 \mathrm{~b} \\ & \\ \text { Bath University (UKOLN) } & 2 \\ \text { Leeds Metropolitan University } & 2 \\ \text { Liverpool John Moores University } & 2 \\ \text { University of Central Lancashire } & 2 \\ \text { University College London } & 2 \\ & \\ \text { Bath College of HE } & 1 \\ \text { La Sainte Union College of HE } & 1 \\ \text { Thames Valley University } & 1\end{array}$

\title{
IT POINT: A public library IT demonstrator project
}

\section{NIALL MACKENZIE}

School of Information Studies

University of Central England

IT POINT was a 21-month project that brought public access to information technology and networks within a public library. Chelmsley Wood Library, Solihull, West Midlands, hosted the project under the guidance of the Libraries and Arts Department of Solihull Metropolitan Borough Council. The British Library Research and Innovation Centre (formerly BLRDD) funded the project.

The BLRIC-funded IT POINT project drew to a close on 31 March 1996. However, IT POINT is continuing in service for a further three years as a result of the exit strategies developed during the project by the Project Director Dr Bob McKee, then Director of Solihull MBC's Libraries and Arts Department.

Chelmsley Wood is an area of economic deprivation, where the local community could be expected to be 'information poor'. Chelmsley Wood Library was chosen to house the project as it also offered:

- $\quad$ an appropriate building 
- a clearly defined community within its catchment area

- well developed networks to bring together local interest groups

- a mixed community

- $\quad$ specific local commitment to promote and develop North Solihull.

A range of electronic information services were made available to the public at Chelmsley Wood Library, including:

- Internet access

- electronic mail

- CD-ROMs

- software applications including; word-processing, spreadsheet, desktop publishing, graphics, database

- printing; black and white (laser) and colour (inkjet).

These were provided free of charge (except for printing) for the first year of the project (August 1994 - September 1995) with charges introduced for all of the above services from 1 October 1995.

In October 1995 the Centre for Information Research and Training (CIRT) at the University of Central England (UCE) was contracted to research and evaluate IT POINT's organisation and impact. CIRT was also contracted to write the final project report, with recommendations and transferable models of public access IT facilities for other public library authorities. This work was carried out by Clare Nankivell, Research Associate and Niall MacKenzie, Research Assistant, under the directorship of Professor Judith Elkin, Head of School of Information Studies at UCE.

This article presents the research methodology employed for the evaluation of the project both internally and externally. It will examine the preparatory research, the initial evaluation methodology, the work of the external Evaluation Team and their difficulties and successes and how the evaluation techniques might have been refined.

\section{Preparatory research}

Before the project commenced, Paul Harris, a graduate trainee with Solihull MBC, undertook a piece of customer research within the Chelmsley Wood community in Spring 1994. His findings are referred to in the project Interim Report at the end of 1994 (six months into the project) under Market Research and appear as a lengthy appendix. The report's Market Research Interim Conclusions are brief in comparison with little focus on the local community interest. Paul Harris' work clearly highlighted a high level of interest. He stated:

"in excess of 40 people and groups are actively interested in the project, giving the incoming project manager a firm initial source of contact within the community."

"...all those interviewed showed a genuine interest in the project.... This seems to bode well for the acceptance and use of the system in the future."

The local community representatives he interviewed included those from schools, churches, residents' associations, job centres and Chamber of Commerce and Industry.

It was anticipated that links with these representatives would be maintained for the duration of the project by forming a Community Forum or Local advisory Group. However, this plan to provide 
a platform for local needs and concerns never came to fruition. Two scheduled meetings failed to take place as insufficient numbers could attend and the strong initial contact with local community representatives began to weaken. This must now be seen as a lost opportunity and the local support and goodwill towards IT POINT was largely left untapped.

The Interim Report also referred to early attempts at market research being "cut short" and the "postponement of a number of further market research exercises". The implementation of postal surveys of IT POINT members, particularly Internet users, self-completion surveys and face to face surveys were planned for January 1995. The possibility of filming some of the interviews and involving Queen Margaret College, Edinburgh was discussed although neither became a part of the project.

\section{Proposed evaluation}

The original project proposal recognised the importance of assessing the impact of IT POINT on the local community in terms of:

- appropriateness of services and sources

- levels of community support and involvement

- measurable benefits for individuals and for the community.

The proposal detailed a variety of methods to be used to assess impact, including:

- longitudinal studies of patterns and levels of use within specific groups and the general public

- structured feedback

- case studies

- $\quad$ using existing reference services as a control.

It was also envisaged that evaluation would be an iterative process involving techniques such as; surveys, self-completion questionnaires, structured interviews, user observation and transaction logging of terminal activity. Outside research expertise was suggested as a way of giving the evaluation authority and credibility, seeking the help of a market research organisation (e.g. MORI). Three specific areas of evaluation were anticipated:

- Marketing

- awareness of IT POINT

- volume of use as a percentage of potential users

- how users learned about the service

- Patterns of use

- volume of use measured over time

- adoption of the service

- comparison of the take up of alternative services

- user reaction and levels of satisfaction

- direct user or mediated access

- Impact on and value to the local community

- structured feedback from relevant groups throughout the project

- feedback on the social, educational, economic and other perceived benefits.

In the IT POINTInterim Report there was very little evidence of any on-going evaluation. It became clear at an early stage of the project that the day to day running of IT POINT and the national 
networking and dissemination undertaken left IT POINT staff little time for evaluative work. It is interesting to note, however, that evaluation had no mention in the Problem Areas and Solutions section of the Interim Report.

Service Usage Monitoring was described as, "one of the most important single elements of the Project" in the Interim Report. Monitoring statistics were initially collected manually but the intention was to "develop and/or exploit existing software to provide overall machine usage figures and to link to automatic market research using interactive multimedia techniques". The latter never came into being, although the manual collection of usage statistics was very thorough.

Usage statistics were recorded using:

- booking forms showing membership number and sessions booked

- machine usage recording membership number, machine used, resource used, date, start and finish times

- CD-ROM usage forms recording the same details as machine usage forms but with CD-ROM title also noted

- customer assistance forms, showing membership number, resource for which the assistance was required and member of staff who assisted.

The records were a little unclear at the outset but once the forms were refined they provided an excellent data source.

The membership data recorded were:

- date of joining

- title, name, address, postcode

- telephone number

- child

From 10th August 1995 the following were also recorded to meet European funding requirements:

- date of birth

- highest qualification

- gender

- age

- disability

- employed in secure/threatened employment

- unemployed (and length of time unemployed)

- ethnic origin

- student

Unfortunately, the comprehensiveness and accuracy of the membership data did not match that of the usage statistics. The introduction of the additional data fields came too late to provide the Evaluation Team with a satisfactory way of cross-referencing the usage data.

Particularly disappointing were the inaccurate and incomplete age statistics. Only noting whether a member was a child for the first year of the project made demographic profiling of the membership difficult. An accurate and complete record of the IT POINT membership would have been an invaluable source for analysis. 


\section{The Evaluation Team methodology}

As discussed, very little evaluation of IT POINT had taken place prior to CIRT's contract. Staff at IT POINT had kept records of all publications, presentations and other activities undertaken and had partially analysed monthly usage and membership records kept. Unfortunately, a complete set of usage data was not available to the Evaluation Team as four month's data records were missing - CIRT had to analyse usage with a 'data gap' from 31st December 1994 to 1st May 1995.

The Evaluation Team was faced with having to evaluate a 21 -month project during its final six months. To achieve this a number of methodologies were employed:

- analysis of IT POINT resources and services

- questionnaire survey of all IT POINT members to focus on use, impact and perceptions. Interviews with a small sample of questionnaire respondents

- interviews with library staff, community representatives and the general public

- analysis of all questionnaires, interviews and surveys conducted by or on behalf of IT POINT

- design of a database to record all usage records, entering of all the data and analysis of usage and membership

- meetings with Project Director and Manager to discuss IT POINT's history and collect related documents.

The Evaluation Team had to remove staff usage from the usage statistics. It was quite a difficult process deciding which users were staff and what was staff usage or not. For example, the casual assistant, appointed in August 1995 had been one of IT POINT's heaviest users prior to his appointment, so all of his subsequent usage was removed. Conversely, some library staff had joined IT POINT but then left the library.

Another very significant finding was that although IT POINT had made an impact on the local community, this was patchy. The initial marketing of IT POINT was seen by the project team as very successful and the demand for services was initially so high that the marketing strategy became relaxed. Word of mouth was regarded as the best form of marketing, which it may well have been. However, only particular sectors of the community had learned about IT POINT.

When local community group leaders were interviewed by the Evaluation Team, for some it was the first contact from IT POINT since the preparatory research interview with Paul Harris. The representative for the Solihull Chamber of Commerce and Industry felt that the Chamber would have been able help IT POINT develop and maintain links with local businesses and an opportunity might have been missed.

Interviews with the general public, community representatives and analysis of the usage statistics were the main evaluation tools for impact on the local community. However, the Evaluation Team had great difficulty in evaluating the impact for two main reasons:

- this evaluation would have been best conducted as an ongoing part of IT POINT's work, from the project staff

- community networks had not been developed by the original Project Manager, which the Evaluation Team could have used. 
The value of the Evaluation Team's input was increasingly recognised in the shaping of the final report. Independent external research was vital in terms of objectivity. The Steering Group wholeheartedly supported a "warts and all" style for the final report as this was a demonstrator project from which others should learn. An external Evaluation Team was not seen as threatening to those closely involved with the project.

\section{Lessons for the future}

The experiences of IT POINT suggest that successful development projects benefit from:

- ongoing evaluation

- external evaluation

- opportunities to learn from evaluation results early and react to them.

Ongoing evaluation of IT POINT would have been desirable to everyone associated with the project. Ideally, all of this evaluation should have been carried out by an external Evaluation Team but it would have been costly to fund external evaluation for 21 months. A research adviser appointed to the project from the outset, working with project staff and helping to develop the evaluation tools and instruments, would have been more practicable. For example, the automated statistic collection might have been more feasible with the assistance and advice of an external Evaluation Team.

External evaluation would have enabled IT POINT staff to concentrate less on the day to day running of the project and more on the strategic management, marketing and the local community forum. The Evaluation Team would also have been able to feed into the on-going dissemination enabling progressive project development. The problem of evaluation using unfamiliar instruments would also have been avoided.

The Evaluation Team also highlighted the fact that although IT POINT had been successful in its local acceptance and integration, even closer links with the community, local businesses and embracing the CWL staff into the project would have enriched what was a well conceived and well run demonstrator project.

For further information please contact:

Niall MacKenzie

Research Assistant

School of Information Studies

Centre for Information Research and Training

Faculty of Computing and Information Studies

Perry Barr

Birmingham

B42 2SU

Tel: 0121-331 5619

Fax: 0121-331 5675

Email: Niall.MacKenzie@uce.ac.uk 
The final report for IT POINT can be purchased as photocopies or microfiche from the British Thesis Service, British Library Document Supply Centre, Boston Spa, Wetherby, West Yorkshire, LS23 $7 \mathrm{BQ}$.

A summary of the report can be found at:

http://www.itpoint.org.uk/research.html

The use of library footage in the production of television news: a case study of BBC TV's "Newsroom South East" programme.

\section{ROBIN PEARSON}

\section{Background}

The catalyst for this piece of research was the introduction by the BBC in 1992 of a cost accounting scheme known as Producer Choice. Prior to this, all BBC resource departments had their own budgets and provided what was in essence a 'free' service to programme makers.

With the advent of Producer Choice all budgets were transferred to the programme makers themselves. They now hold the purse strings and can choose whether to purchase the services they require from either 'in house' $\mathrm{BBC}$ departments, or from outside the Corporation altogether. As a result, all $\mathrm{BBC}$ resource departments now have to be self financing within this new, more competitive market place.

The study was based at the Videotape (VT) Library at BBC Elstree. Its main role is to supply moving image material to the local regional news magazine 'Newsroom South East' (NSE). This half hour programme is broadcast from Elstree, Monday to Friday, at $6.30 \mathrm{pm}$.

As a result of Producer Choice, the Elstree Library now relies upon selling its services to NSE. In this new commercial relationship there is a’need to be able to quantify the service that the Library provides. It was this need that provided the central impetus behind this research project. The resulting analysis should not only enable the Library to be more conscious of the demands placed upon it by NSE, but should also allow it to demonstrate to the programme makers what an essential role it plays in getting NSE 'on the air'.

\section{Aims}

The following were identified as key aims in quantifying the role of the library in supplying material for NSE.

- To establish how much of NSE is made up of library footage

- To establish the amount of library footage used by different types of stories within NSE. For example, do Transport stories place a greater demand on the library than Sport stories? This has important implications for decisions on the retention of material. 